Research Paper:

\title{
The Effectiveness of Training Based on Positive Psychology on the Quality of Life of Patients With Type 2 Diabetes
}

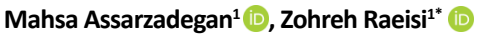 \\ 1. Department of Clinical Psychology, Najafabad Branch, Islamic Azad University, Najafabad, Iran.
}

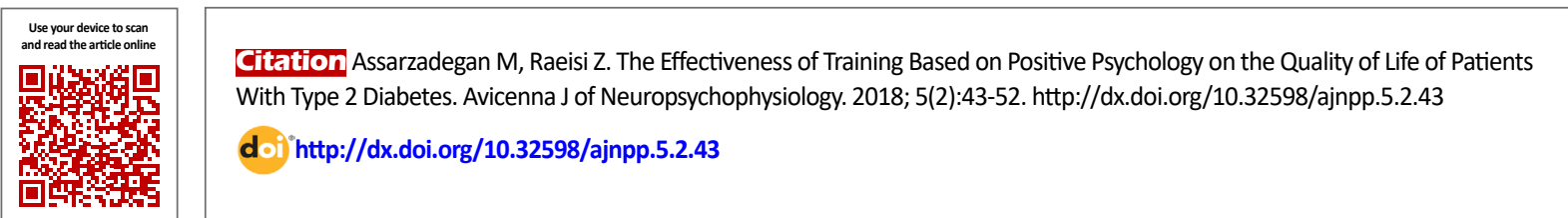

\section{(i) (\$)}

Article info:

Received: 10 Jan 2018

Accepted: 23 Mar 2018

Available Online: 01 May 2018

Keywords:

Training, Positive psychology, Quality of life, Type 2 diabetes

\section{A B STRACT}

Introduction: Diabetes is one of the most common chronic diseases, which has a negative effect on the quality of life.

Objectives: The aim of this study was to investigate the effectiveness of training based on positive psychology on the quality of life of patients with type 2 diabetes.

Materials and Methods: This quasi-experimental study had a Pre-test-Post-test with a control group and a follow-up design. The sample was selected through the convenience sampling method from patients with type 2 diabetes in Hazrat Ali Health center in Isfahan in 2017; then, they were randomly divided into 2 groups (each group contained 15 individuals). The experimental group was trained with positive psychology and the control group did not receive any treatment. Both groups were evaluated before and after the intervention and at the follow-up stage, using the World Health Organization Quality of Life questionnaire. The data were analyzed by the analysis of variance with repeated measurements.

Results: The results showed that positive psychological education had a significant influence on the quality of life and mental health area, social relations, and environmental health in patients with type 2 diabetes. Also, there was a significant difference between the experimental and control groups; but in the physical health area, there was no significant difference between the experimental and control groups $(\mathrm{P}<0.001)$.

Conclusion: Positive psychological education effectively improves the quality of life of patients with type 2 diabetes. Therefore, it is recommended to use this treatment approach to help improve the quality of life of these patients.

\section{* Corresponding Author:}

Zohreh Raeisi, PhD.

Address: Department of Clinical Psychology, Najafabad Branch, Islamic Azad University, Najafabad, Iran.

Tel: +98 (939) 1359601

E-mail: z.tadbir@yahoo.com 


\section{Introduction}

iabetes is one of the chronic and problematic diseases of humans for years. It has happened in different ages and has an alarming prevalence [1]. It is described as a chronic disease caused by an abnormality in the metabolism of carbohydrates, proteins, and fat [2]. Diabetes is defined as a disorder in homeostasis, which includes disorder in fasting glucose and disorder in glucose tolerance. Plasma glucose, which increases the risk of diabetes in this definition, is the level of fasting blood glucose $(126 \mathrm{mg} / \mathrm{dL})$ or blood glucose 2 hours after eating $(200 \mathrm{mg} / \mathrm{dL})$ [3].

Epidemiological data show that the number of people with diabetes will be double if this increase is particularly about type 2 diabetes [4]. Type 2 diabetes is a chronic multifactorial disorder that is associated with hyperglycemia and damage to organs in the long term [5]. Type 2 diabetes is non-insulindependent diabetes or adult diabetes. About $90 \%$ to $95 \%$ of people get type 2 diabetes. The cause is unknown and it is because of the destruction of stem cells. Overweight or obesity is one of the causes of type 2 diabetes. Overweight causes insulin resistance [6]. The prevalence of diabetes has increased in recent years, and its risk has increased by $40 \%$ over the past 26 years [7]. According to the recent World Health Organization, the prevalence of diabetes and its related risk factors in Iran was $9.6 \%$ in men, $11.1 \%$ in women, and $10.3 \%$ in the overall population [8]. According to studies by the International Federation of Diabetes, the number of people with diabetes worldwide has reached 425 million in 2017 and is predicted to reach 629 million in 2045 [9].

The life condition of patients with type 2 diabetes is often reported as having a lower quality of life [10]. The quality of life of patients with type 2 diabetes is affected by disease and its complications, such as retinopathy, neuropathy, and cardiovascular disease because of the chronic condition of illness, disability, and lifetime need for care and it endangers their mental health $[11,12]$. In fact, the chronic nature of the disease affects the body, mental, individual, and social function of the patient. Therefore, studying the different dimensions of the quality of life of patients with diabetes is important [13].

Diabetes is a major challenge for healthcare professionals because it affects the patient's psychosocial function and, thus, threatens the quality of life associated with health [14]. There is an interaction between illness and quality of life, especially for those with chronic illnesses, who are involved in many issues throughout life, and physical signs and disorders have a direct effect on all aspects of quality of life [15].
Several studies have shown that the quality of life in patients with diabetes is reduced in comparison to those without diabetes. Moreover, the presence of complications of diabetes has more negative effects on the quality of life of the person [16]. In 2014, Eydi Baygi et al. showed a significant difference between the life quality of patients with and without diabetes [17]. Also, Shokouhi Far and Fallahzadeh in 2014 concluded that diabetes is a chronic disease that affects the quality of life [18].

Considering the connection among the quality of life, mental health, and the high prevalence of psychological problems in patients with diabetes, effective interventions to improve the status of mental health and the quality of life of patients are necessary [19]. In fact, improving the quality of life of patients with type 2 diabetes is highly emphasized in the clinical guidelines of diabetes control; one of the primary goals of diabetes control is improving the quality of life [20]. Over the past 2 decades, the results of studies have shown that the main goal of the treatment is not only eliminating the signs and symptoms of the disease but also improving the overall quality of life of patients. In order to achieve this goal, attention must be paid to the psychological and social consequences of the illness. The quality of life is important because if it is neglected, it can lead to disappointment, the lack of motivation, and reduced social, economic, cultural, and health activities [21].

Therefore, because of the importance of psychological constructs in patients with type 2 diabetes, specialists have suggested several psychological interventions [2224]. Positive psychological interventions are a potential new approach to increase the positive psychological structures in psychology, which seems to have positive psychological structures (such as optimism, the effect of positive affection) with different health outcomes [25]. In fact, positivist interventions can reduce depression, increase happiness and psychological well-being in individuals through increasing positive emotional excitement, positive thoughts, positive behaviors, and satisfaction of the basic needs of individuals such as autonomy, love, and communication [26]. It emphasizes the enhancement of human abilities and virtues, enabling individuals and societies to succeed [27].

Several studies have been conducted to examine the effectiveness of positive psychology; for example, the studies of Masi et al. [28] and Hoffman et al. [29] showed that positive psychological intervention is effective in improving the health outcomes of patients with diabetes and the results of the research by De Bois showed that the positive psychological program would 
improve mental health, performance, and health in patients with type 2 diabetes [30]. Therefore, the use of group counseling programs, especially psychotherapy, improves physical, emotional, and social performance, decreases fatigue, and reduces the negative effects of this disease [31].

Positive thinking skills include the teaching of thinking differently both about positive thoughts and events and negative thoughts and events and consider value for having this skill. In positive thinking, individuals are encouraged to recognize their positive experiences and their strong points and recognize their role in enhancing self-esteem and improving their lives [32]. The prevalence of type 2 diabetes and the negative effects of this chronic disease on the quality of life of the patients, considering its future effects, as well as the need to select appropriate interventions to correct it, the lack of research on the effectiveness of education based on positive psychology on the quality of life and its dimensions in patients with type 2 diabetes show the necessity of this research.

Therefore, the aim of this study was to investigate the effectiveness of positive psychological education on the quality of life and its dimensions in patients with type 2 diabetes.

\section{Materials and Methods}

In terms of the aim, this study was applied research and in terms of the data collection, it had a Pre-testPost-test with a control group and follow-up design. The statistical population of the present study included all the patients with type 2 diabetes from the health centers of Isfahan in 2017. In order to sample the patients with type 2 diabetes referred to Hazrat Ali comprehensive health center, 30 patients were selected according to the availability and the inclusion criteria; they were, then, randomly divided into 2 groups (each group contained 15 individuals). It is worth noting that 2 of the experimental group and 2 of the control group were excluded from the research project because of their unwillingness to continue the study.

The inclusion criteria included the diagnosis of type 2 diabetes with blood tests and physician's diagnosis, age between 30 and 65 years old, competence in reading and writing skills, and satisfaction with participation in the research; the exclusion criteria included unwillingness to continue cooperation, failure to perform the provided assignments at the meetings, absences for more than 2 sessions, and acute or chronic psychiatric disorders recognized by the psychiatrist.

The world health organization Quality of Life Questionnaire was used to collect the data. It contains 26 questions and measures 4 areas, including physical health, mental health, social relationships, and environmental health with 24 items (each with 3, 6, 7, and 8 questions, respectively). Two questions do not belong to any of the areas and generally assess the general health and quality of life. A score of 4 to 20 will be obtained for each area, in which 4 is the worst sign and 20 is the best condition of that field. These scores can be converted into the amplitude of scores from at least zero to 100 as maximum. According to the results reported by the World Health Organization Quality of Life Questionnaire, in the 15 international centers of the organization, the Cronbach's alpha is between 0.73 and 0.89 for the 4 subscales and the whole scale, respectively. In Iran, Nassiri used 3 kinds of retest with a 3-week interval and the Cronbach's alpha for the reliability of the scale was $0.70,0.87$, and 0.87 , respectively.

Thirty people were chosen based on the inclusion criteria and the available sampling method and they were randomly divided into the experimental and control groups. Before applying the intervention, the World Health Organization Quality of Life Questionnaire was delivered to both groups for the Pre-test. There was no intervention for the control group. Then, for the experimental group, 8 sessions (90 minutes for each session) of positive psychological education were performed; then, the test was repeated for both groups. In order to maintain the effect of education, both groups were followed-up 1 month later.

To observe the ethical considerations of the study, before distributing the questionnaires, informed consent was obtained from the samples. The method of implementing the intervention and the optionalness of the company in the research were explained to the participants to ensure them about the better cooperation and the confidentiality of the information. They were assured that the data of the research questionnaire would be analyzed and used only in relation to the goals and hypotheses of the research. Positive psychological training sessions were conducted based on the Rashid and Seligman treatment protocol that is described in Table 1.

In order to analyze the research data, SPSS V. 22 software was used. Also, the mean and Standard Deviation (SD) of scores were used at the descriptive level and repeated 
Table 1. Pandects of formation of positive psychological sessions

\begin{tabular}{|c|c|}
\hline Sessions & Training content \\
\hline First & $\begin{array}{l}\text { Familiarizing members with each other, the initial communication, directing the patient to the atmosphere of posi- } \\
\text { tive psychology, and self-introduction of patients in a positive way. }\end{array}$ \\
\hline Second & $\begin{array}{l}\text { Presentation of the summary of the previous session and its review, the expression of the main concepts in positive } \\
\text { thinking, the identification of signs and symptoms of positive thinking, the assessment of abilities and helping the } \\
\text { patient to develop positive abilities. }\end{array}$ \\
\hline Third & $\begin{array}{c}\text { Presentation of the summary of the previous session, helping the patient to understand the role of good and bad } \\
\text { memories, providing an appreciation notebook, writing } 3 \text { good memories, writing } 3 \text { bad memories, expression of } \\
\text { the negative emotions, and providing assignments about that. }\end{array}$ \\
\hline Fourth & $\begin{array}{l}\text { Presentation of the summary of the previous session, turning negative to positive emotions, focusing on apprecia- } \\
\text { tion and forgiveness, and providing assignments about that. }\end{array}$ \\
\hline Fifth & Presentation of the previous session focused on the topic of hope and optimism, reviewing the contents. \\
\hline Sixth & $\begin{array}{l}\text { Presentation of a summary of the previous session, love and attachment, positive relationship with others, review } \\
\text { of response styles (active-constructive response), and presentation of assignments in the same direction. }\end{array}$ \\
\hline Seventh & $\begin{array}{l}\text { Presentation of the summary of the previous session, the art of having and feeling the pleasure, the presentation of } \\
\text { assignments about that. }\end{array}$ \\
\hline Eighth & $\begin{array}{l}\text { Integration of the lessons, creating a positive environment, maintaining health and its impact on positive psychol- } \\
\text { ogy, and feedback. }\end{array}$ \\
\hline
\end{tabular}

AJNPP

measures Analysis of Variance (ANOVA) was used at the inferential level.

\section{Results}

The Mean $\pm S D$ age of the experimental and control groups was $44.54 \pm 7.52$ and $46.85 \pm 7.87$ years, respectively. In the experimental group, $46.2 \%$ of the partici- pants were male and $53.8 \%$ were female; in the control group, $61.5 \%$ of the participants were male and $38.5 \%$ were female, and $53.8 \%$ female and $46.2 \%$ male overall.

Descriptive findings were used to examine the mean and SD of the variables in the research. Table 2 presents the mean and SD of the variables.

Table 2. Descriptive findings of the studied variables in the experimental and control groups

\begin{tabular}{cccc}
\hline Variables & Stage & \multicolumn{2}{c}{ Mean \pm SD } \\
\cline { 3 - 3 } $\begin{array}{c}\text { Quality of } \\
\text { Life }\end{array}$ & Pre-test & $43.4 \pm 23.53$ & Control \\
\hline & Post-test & $80.2 \pm 76.68$ & $69.51 \pm 57.4$ \\
& Follow-up & $30.3 \pm 61.64$ & $53.50 \pm 44.4$ \\
Physical health field & Pre-test & $98.1 \pm 53.15$ & $46.43 \pm 41.5$ \\
& Post-test & $16.2 \pm 14.00$ & $73.1 \pm 31.00$ \\
Mental health field & Follow-up & $30.14 \pm 25.1$ & $53.1 \pm 23.13$ \\
& Pre-test & $97.1 \pm 92.13$ & $25.2 \pm 53.12$ \\
& Post-test & $76.16 \pm 64.1$ & $66.1 \pm 61.13$ \\
Social relation field & Follow-up & $73.1 \pm 0.17$ & $84.11 \pm 14.1$ \\
& Pre-test & $38.5 \pm 26.1$ & $97.13 \pm 30.10$ \\
& Post-test & $84.8 \pm 0.898$ & $60.1 \pm 15.5$ \\
& Follow-up & $76.8 \pm 10.1$ & $16.6 \pm 14.1$ \\
& Pre-test & $66.1 \pm 53.16$ & $84.6 \pm 24.1$ \\
\hline Environment health field & Post-test & $30.20 \pm 21.2$ & $84.15 \pm 23.2$ \\
& Follow-up & $92.21 \pm 18.1$ & $92.16 \pm 36.2$ \\
\hline
\end{tabular}


Table 3. The results of the Kolmogorov-Smirnov test and Levene's test

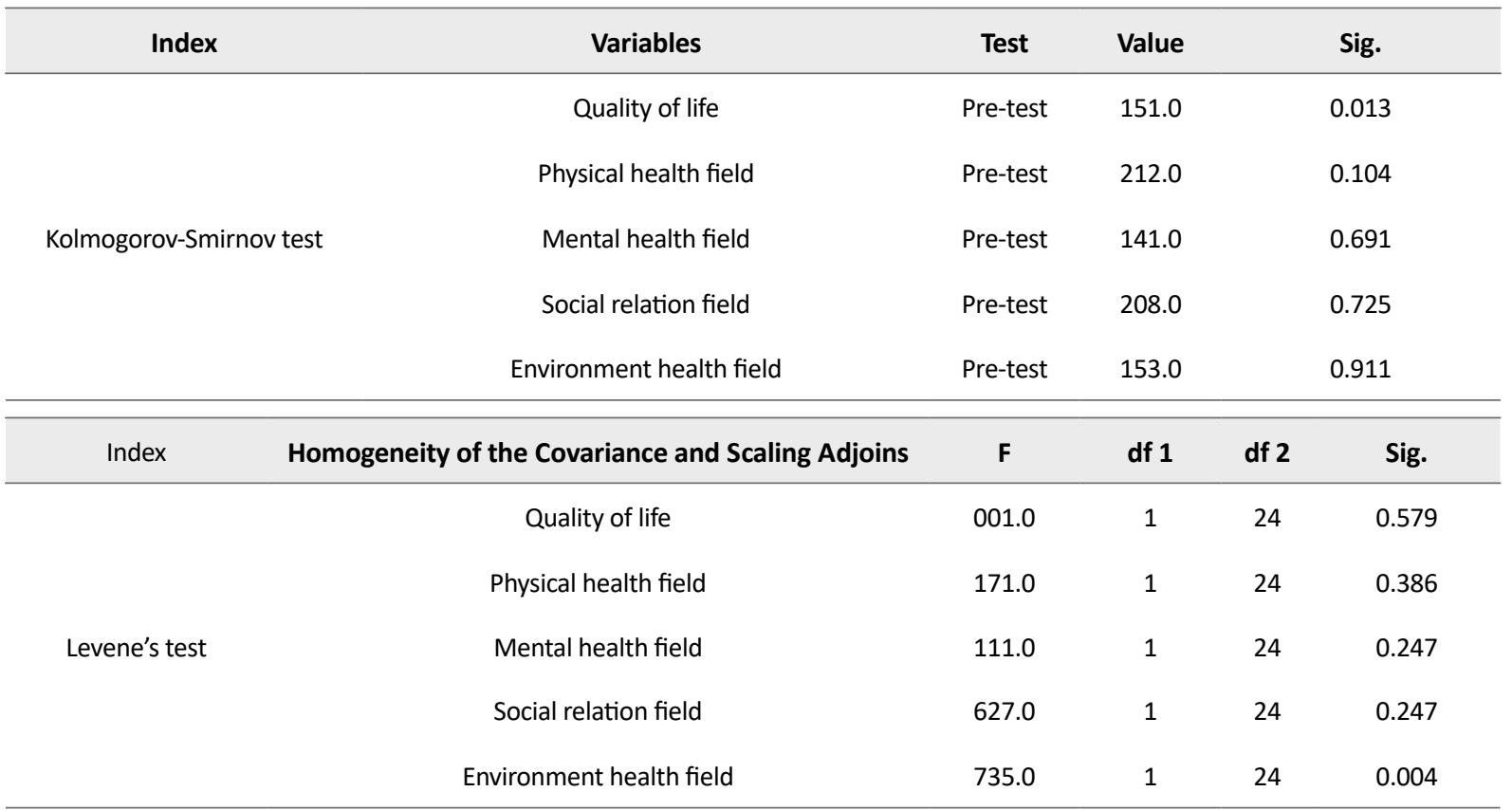

According to Table 2, in the pre-test stage, there was no significant difference between the experimental and control groups; however, in the Post-test stage, the scores of quality of life, the field of physical health, the field of mental health, the field of social relations, and the field of the health of the environment increased in the experimental group. In order to implement a repeated measure of ANOVA, we first need to examine the assumptions of performing ANOVA.

Based on Table 3, the results of the KolmogorovSmirnov a nd Levene's tests show that the data are consistent with the normal distribution and the homogeneous assumption of ANOVA. The results of the Kolmogorov-Smirnov test showed the normal distribution of the scores of dependent variables. Also, the results of the Levene's test showed that the significance level obtained for both groups in the de pendent variables was 0.95 , indicating that the experimental and control groups are the same in terms of score scattering of the dependent variables.

According to Table 4 and the significance of factors within the groups, there was a significant difference between the measurements of Pre-test, Post-test, and follow-up for the quality of life; the areas of patient's physical health, mental health, social relationships, health of the environment Type 2 diabetes were confirmed at $P<0.001$. Also, with the significance of the source of the group among the groups, it can be said that there is a significant difference between the experimental group and the control group for the of quality of life, mental health, social relations, and health of the environment of patients with type 2 diabetes at the level of $\mathrm{P}<0.001$; it means that positive psychological education was effective in the quality of life, mental health, social relations, and the health of the environment in patients with type 2 diabetes, but this intervention had no effect on the physical health of this group.

In order to investigate the difference between the mean of the studied scale among Pre-test, Post-test, and follow-up measurements, the Bonferroni post hoc test was used as a paired test. The results of this test are presented in Table 5.

According to Table 5, the Pre-test scores with Post-test and follow-up of the quality of life, the mental health field, the field of social relations, and the health of the env i ronment field have a significant difference. The Post-test scores in the follow-up scale are relatively constant and the effect of the training positive psychology for the quality of life on mental health, the field of social relations, and the field of health of the environment are also persistent. These results indicate that positive psychological education was effective in the quality of life, mental health, social relations, and the field of health of the environment. Moreover, in reducing the effectiveness of this treatment, the time was not effective through the Post-test to followed-up. According to the 
Table 4. ANOVA among subjects and inside subjects with 3 measurements: Pre-test, Post-test, and follow-up for quality of life, physical health, mental health, social relationships, and healthy environment of patients with type 2 diabetes

\begin{tabular}{|c|c|c|c|c|c|c|c|}
\hline Source & $\begin{array}{l}\text { Sum of } \\
\text { Squares }\end{array}$ & $\begin{array}{l}\text { Freedom } \\
\text { Degree }\end{array}$ & $\begin{array}{l}\text { Mean of } \\
\text { Squares }\end{array}$ & $\mathbf{F}$ & Sig. & Eta & Statistical Power \\
\hline \multirow{3}{*}{$\begin{array}{l}\text { Error interac- } \\
\text { tive factor }\end{array}$} & 154.779 & 2 & 577.389 & 219.19 & 0.00 & 0.544 & 0.01 \\
\hline & 872.2685 & 2 & 936.1342 & 251.66 & 0.00 & 0.437 & 0.01 \\
\hline & 974.972 & 48 & 270.20 & & & & \\
\hline \multirow{2}{*}{ Error group } & 013.5400 & 1 & 013.5400 & 229.453 & 0.00 & 0.059 & 0.01 \\
\hline & 949.285 & 24 & 915.11 & & & & \\
\hline \multirow{3}{*}{$\begin{array}{l}\text { Error interac- } \\
\text { tive factor }\end{array}$} & 564.1919 & 2 & 782.959 & 641.360 & 0.00 & 0.839 & 0.01 \\
\hline & 026.92 & 2 & 013.46 & 289.17 & 0.00 & 0.914 & 0.01 \\
\hline & 744.127 & 48 & 661.2 & & & & \\
\hline \multirow{2}{*}{ Error group } & 821.160 & 1 & 821.160 & 752.77 & 0.404 & 0.460 & 0.132 \\
\hline & 641.49 & 24 & 068.2 & & & & \\
\hline \multirow{3}{*}{$\begin{array}{l}\text { ERROR interac- } \\
\text { tive factor }\end{array}$} & 333.6 & 2 & 167.3 & 928.19 & 0.200 & 0.735 & 0.658 \\
\hline & 256.141 & 2 & 628.70 & 704.20 & 0.00 & 0.364 & 0.01 \\
\hline & 744.163 & 48 & 411.3 & & & & \\
\hline \multirow{2}{*}{ Error group } & 013.308 & 1 & 013.308 & 197.157 & 0.00 & 0.868 & 0.01 \\
\hline & 026.47 & 24 & 959.1 & & & & \\
\hline \multirow{3}{*}{$\begin{array}{l}\text { Error interac- } \\
\text { tive factor }\end{array}$} & 792.50 & 2 & 397.25 & 880.32 & 0.00 & 0.875 & 0.01 \\
\hline & 795.50 & 2 & 397.25 & 880.32 & 0.00 & 0.875 & 0.01 \\
\hline & 07.37 & 48 & 772.0 & & & & \\
\hline \multirow{2}{*}{ Error group } & 128.123 & 1 & 128.123 & 771.62 & 0.00 & 0.327 & 0.01 \\
\hline & 077.47 & 24 & 962.1 & & & & \\
\hline \multirow{3}{*}{$\begin{array}{l}\text { Error interac- } \\
\text { tive factor }\end{array}$} & 641.78 & 2 & 321.39 & 688.9 & 0.00 & 0.882 & 0.679 \\
\hline & 538.282 & 2 & 269.141 & 806.34 & 0.00 & 0.295 & 0.01 \\
\hline & 821.194 & 48 & 059.4 & & & & \\
\hline \multirow{2}{*}{ Error group } & 385.415 & 1 & 385.415 & 267.110 & 0.100 & 0.128 & 0.01 \\
\hline & 460.90 & 24 & 767.3 & & & & \\
\hline
\end{tabular}


Table 5. Bonferroni post hoc test for comparing the quality of life, mental health, social relations, and environmental health as a pair in the time series

\begin{tabular}{|c|c|c|c|c|c|}
\hline Scale & Stage A & Stage B & Mean difference (A-B) & Standard error & Sig. \\
\hline \multirow{4}{*}{ Quality of life } & & & 019.7- & 850.0 & 00.0 \\
\hline & Pre-test & Follow-up Post-test & & & \\
\hline & & & 077.6 & 443.1 & 00.0 \\
\hline & Post-test & Follow-up & 115.1 & 379.1 & 915.0 \\
\hline \multirow{4}{*}{ Mental health area } & & & $538.0-$ & 460.0 & 00.0 \\
\hline & Pre-test & Follow-up Post-test & & & \\
\hline & & & 115.0 & 625.0 & 00.0 \\
\hline & Post-test & Follow-up & 154.0- & 430.0 & 425.0 \\
\hline \multirow{4}{*}{ Social relation area } & & & 731.1- & 193.0 & 00.0 \\
\hline & Pre-test & Follow-up Post-test & & & \\
\hline & & & $962.1-$ & 297.0 & 00.0 \\
\hline & Post-test & Follow-up & 038.0 & 230.0 & 918.0 \\
\hline \multirow{3}{*}{$\begin{array}{l}\text { The health of the } \\
\text { environment area }\end{array}$} & & & 423.2- & 441.0 & 00.0 \\
\hline & Pre-test & Follow-up Post-test & 846.0- & 566.0 & 00.0 \\
\hline & Post-test & Follow-up & 577.1 & 650.0 & 069.0 \\
\hline
\end{tabular}

results, the education based on positive psychology is effective in the quality of life, mental health, the field of social relationships, and health of the environment of patients with type 2 diabetes and remains stable for 1 month.

\section{Discussion}

The aim of this study was to provide a positive psychological education on the quality of life in patients with type 2 diabetes. Based on the results, positive psychological education had an impact on the quality of life and led to improvements in the quality of life; the effect of this treatment was stable after 1 month and the results of this study were in line with the results of many studies based on the effect of treatment and education on positive psychology. In a study, Jalali et al. evaluated the effectiveness of positive psychotherapy on the quality of life of spouses of neurology and psychiatry veterans; it was concluded that positive psychotherapy education increased the psychological well-being and the quality of life in the experimental group in comparison with the control group in the Post-test stage [33-35]. The results of Shahid Golami's research indicate the effectiveness of positive psychological therapy on improving the quality of life of multiple sclerosis patients [36]. Soheilizadeh et al. found that improving self-esteem and resilience and providing appropriate strategies could improve the quality of life of patients with type 2 diabetes [37]. The results of studies by Diener and Chan [38] and Sin et al. [39] showed that positive thinking is effective in improving the quality of life. In the theoretical explanation of these findings, it can be said that positive psychological education can help improve the quality of life in order to strengthen and improve the positive relationship with oneself, others, and life and increase self-esteem. Also, the training of optimism and positive thinking skills encourages patients with diabetes to notice positive and good experiences and their role in increasing respect for themselves and others rather than reminding negative thoughts about their illnesses and their constraints [40]. Generally, positive psychosocial education by creating positive thinking leads to a happy life, a better way of looking at life rather than focusing on illness and its symptoms and limitations. Attention to positive emotions, positive sources of energy, positive energy transfer to others, the reduction of psychological stress and self-confidence may have contributed to the improvement of quality of life in patients with type 2 diabetes [41]. Also, Tabataba'i and Manafi, in line with the present study, stated that the treatment affects the emotions of quality of life [42]. Also, according to Shoshani et al., this intervention has a positive effect on cognitive interactions and social relationships [43]. Yazdi Ravandi 
et al. also concluded that social support and self-efficacy play an important role in predicting the level of compatibility in patients with diabetes. [44]. Fraser et al. reported that positive psychological education is effective in the environmental characteristics of diabetes control and management [45]. In explaining this part of the findings, positive psychological education teaches patients to take an active position in the world and shape their lives personally and to express a clear picture of good life and see the best in every situation and reconstruct themselves; thus, a patient with type 2 diabetes accepts the constraints of his illness and acts by knowing more about his abilities in every situation [46]. By considering the success that has been achieved, they feel more fluent in their own environment.

In explaining the disapproval of the effectiveness of positive psychological education on the physical dimension, it can be stated that the symptoms of diabetes, including frequent urination, excessive thirst, excessive hunger, weight loss, tingling, itching, peripheral neuropathy, acute vagina infections, and fatigue are affected by the individual's compliance with the treatment. It can also be argued that patients with chronic disease, long-term disease, long-term persistent and debilitating treatment, and physical and emotional consequences are among the factors [47]; they are corresponsive with the results of Yazdi Ravandi's research, which concluded that the severity and duration of pain play an important role in predicting the quality of life of patients for chronic pain, especially in the physical domain [48]. Patients with type 2 diabetes appear to have no difference in physical and general health even after the treatment because of the daily feelings of their symptoms, necessity of using drugs on time, and the duration and severity of the disease.

The present study was confronted with the generalization of the results because of the self-reporting of the counseling tool and the lack of neutral counseling sessions for the control group in order to eliminate the effect of group therapy expectations. Other limitations such as the impossibility of random selection of the sample group in the present study were suggested and it would be advisable to conduct random sampling in future studies with larger sample size. Also, conducting longer studies with long-term follow-up and multi-stage is suggested to investigate the continuity of the effectiveness and sustainability of the course of positive psychological education.

\section{Conclusion}

The results of this study showed that the implementation of a health plan and positive psychological education effectively improve the quality of life of patients with diabetes. Also, the use of positive thinking techniques and skills to strengthen and improve positive self-affiliation, positive relationship with others and life, and increased self-esteem can help improve the quality of life. Therefore, it can be expected that providing appropriate strategies such as conducting educational programs with positive thinking, looking at life from its good aspects rather than focusing on disease, and increasing adaptability in patients with diabetes would improve the quality of life of these patients to reduce the complications, problems, and costs of the treatment of this disease.

\section{Ethical Considerations}

\section{Compliance with ethical guidelines}

All ethical principles were considered in this article. The participants were informed about the purpose of the research and its implementation stages; they were also assured about the confidentiality of their information; Moreover, They were allowed to leave the study whenever they wish, and if desired, the results of the research would be available to them.

\section{Funding}

This research did not receive any specific grant from funding agencies in the public, commercial, or not-forprofit sectors.

\section{Authors' contributions}

All authors contributed equally in preparing all parts of the research.

\section{Conflict of interest}

The authors declared no conflict of interest.

\section{Acknowledgments}

The authorities of the health center of Isfahan and the staff of Imam Ali Health Center and the distinguished participants, who helped us in this study are gratefully acknowledged. 


\section{References}

[1] Ngo-Metzger Q, Sorkin DH, Billimek J, Greenfield S, Kaplan SH The effects of financial pressures on adherence and glucose control among racial/ethnically diverse patients with diabetes. Journal of General Internal Medicine. 2012; 27(4):432-7. [DOI:10.1007/ s11606-011-1910-7] [PMID] [PMCID]

[2] Meusel LA, Kansal N, Tchistiakova E, Yuen W, Maclntosh BJ, Greenwood CE, et al. A systematic review of type 2 diabetes mellitus and hypertension in imaging studies of cognitive aging: Time to establish new norms. Frontiers in Aging Neuroscience. 2014; 6(4):148-58 [DOI:10.3389/fnagi.2014.00148] [PMID] [PMCID]

[3] Portero McLellan KC, Wyne K, Villagomez ET, Hsueh WA. Therapeutic interventions to reduce the risk progression form prediabetes to type 2 diabetes mellitus. Jounal of the Therapeutics and Clinical Risk Management. 2014; 10:173-88. [DOI:10.2147/TCRM.S39564] [PMID] [PMCID]

[4] Stankovic Z, Jasovic-Gasic M, Zamklar M. Psycho-social and clinica variables associcated with depression in patients with type 2 diabetes. Psychiatria Danubina. 2011; 23(1):34-44. [PMID]

[5] Srinivasan BT, Davies M. Glycaemic management of type 2 diabetes. Medicine. 2019; 47(1):32-9. [DOI:10.1016/j.mpmed.2018.10.009]

[6] American Diabetes Association (ADA). Classification and diagnosis of diabetes: Standards of medical care in diabetes. Diabetes Care. 2018; 41(suppl. 1): S13-27. [DOI:10.2337/dc18-S002] [PMID]

[7] Gregg E. Management lifetime risk of type 2 diabetes rises to $40 \%$ over 26 years. Available at: http:// www. medical news today.2014. com/articles/280943.

[8] World Health Organization (WHO). Diabetes country profiles 2016 prevalence of diabetes and related risk factors. WHO Diabetes Country Profiles; 2016

[9] Withidpanyawong U, Lerkiatbundit S, Saengcharoen W. Family- based intervention by pharmacists for type 2 diabetes: A randomised controlled trial. Patient Education and Counseling. 2019; 102(1):85-92. [DOI:10.1016/j.pec.2018.08.015] [PMID]

[10] Dyck R, Osgood N, Lin TH, Gao A, Stang MR. Epidemiology of diabetes mellitus among first nations and non-first nations adults. Canadian Medical Association Journal. 2010; 182(3):249-56. [DOI:10.1503/cmaj.090846] [PMID] [PMCID]

[11] Hurtado MD, Vella A. What is type 2 diabetes? Medicine. 2019; 47(1):10-15. [DOI:10.1016/j.mpmed.2018.10.010]

[12] Holmes J, Gear E, Bottomley J, Gillam S, Murphy M, Williams R. Do people with type 2 diabetes and their cares lose in come? (T2ARDIS-4). Health Policy. 2009; 64(3):291-6. [DOI:10.1016/S01688510(02)00177-X]

[13] Tamir O, Wainstein J, Raz I, Shemer J, Heymann A. Quality of life and patient- perceived difficulties in the treatment of type 2 diabetes. Review of Diabetic Studies (RDS). 2012; 9(1):46-54. [DOI:10.1900/RDS.2012.9.46] [PMID] [PMCID]

[14] Adachi M, Yamaoka K, Watanabe M, Nishikawa M, Hida E, Kobayashi I, et al. Effects of lifestyle education program for type 2 diabetes patients in clinics: Study design of a cluster randomized trial. BMC Public Health . 2010; 10:742. [DOI:10.1186/1471-2458-10742] [PMID] [PMCID]

[15] Alijany-Renany H, Tamaddoni A, Haghighyzadeh $\mathrm{MH}$, Pourhosein $\mathrm{S}$. [The effect of using partnership care model on the quality of life in the school-age children with $\beta$ - thalassemia (Persian)]. Journal of Shahrekord University of Medical Sciences. 2012; 14(1):41-9.

[16] Schram MT, Baan CA, pouwer F. Depression and quality of life in patients with diabetes: A systematic review from the European Depression in Diabetes (EDID) research consortium. Current Diabetes Reviews. 2009; 5(2):112-9. [DOI:10.2174/157339909788166828] [PMID] [PMCID]

[17] Eydi Baygi M, Mehrabizadeh M, Davoudi I, Ahmadi V, Dehghanizadeh Z, Babaei B. [Comparison the quality of life in patients with diabetes type 2 and non-diabetic individuals (Persian)]. Journal of Ilam University of Medical Sciences. 2014; 22(5):55-62.

[18] Shokohifar M, Falahzadeh H. [Determination quality of life in patients with type II diabetes and presentation a structural mode (Persian)]. Journal of Mazandaran University of Medical Sciences. 2014; 24(116):84-92

[19] Donard M, Dower J, Coll JR, Baker P, Mukandi B, Doi SA. Menta health issues decrease diabetes-specific quality of life independent of glycaemic controland complication: Findings from Australia's living with diabetes cohort study. Health and Quality of Life Outcomes. 2013; 11:170. [DOI:10.1186/1477-7525-11-170] [PMID] [PMCID]

[20] Bharati DR, Pal R, Rekha R, Yamuna TV. Evaluation of the burden of type2diabetes mellitus in population of Puducherry south india. Diabetes \& Metabolic Syndrome. 2011; 5(1):12-6. [DOI:10.1016/j. dsx.2010.05.008] [PMID]

[21] Hatamloo Sadabadi M, Babapour Kheirodin J. [Comparison of quality of life and coping strategies in diabetic and non diabetic people (Persian)]. Journal of Shahid Sadoughi University of Medical Sciences. 2013; 20(5):581-92

[22] Khoshnood G, Shirkavand N, Ashoori J, Arab Salari Z. [Effects of schema therapy on the happiness and mental health of patients with type II diabetes (Persian)]. Journal of Diabetes Nursing. 2015; 3(1):8-18.

[23] Ashoori J. [The effect of cognitive behavioral therapy on happiness and mental health in patients with type II diabetes (Persian)] Iranian Journal of Psychiatric Nursing (IJPN). 2016; 3(4):71-9.

[24] Zare' Shahabadi A, Ebrahimi Sadrabadi F. [Impact of cognitive factors on treatment of type 2 diabetes in Yazd (Persian)]. Clinical Psychology Studies. 2014; 4(13):1-22.

[25] Amonoo HL, Barclay ME, El-Jawahri A, Traeger LN, Lee SJ, Huffman JC. Positive psychological constructs and health outcomes in hematopoietic stem cell transplantation patients: A systematic review. Biology of Blood and Marrow Transplantation. 2019; 25(1):e516. [DOI:10.1016/j.bbmt.2018.09.030] [PMID]

[26] Lyubomirsky S \& Layous K. How do simple positive activities increase well-being? Current Directions in Psychological Science. 2013; 22(1):57-62. [DOI:10.1177/0963721412469809]

[27] Peterson C, Park N. Orientation to happiness and life satisfaction The full life versus the empty life. Journal of Happiness Studies. 2016; 6(1):25-41. [DOI:10.1007/s10902-004-1278-z]

[28] Massey CN, Feig EH, Duque-Serrano L, Wexler D, Moskowitz JT, Huffman JC. Well-being interventions for individuals with diabetes: A systematic review. Diabetes Research and Clinical Practice. 2019; 147:118-33. [DOI:10.1016/j.diabres.2018.11.014] [PMID]

[29] Huffman JC, DuBois CM, Millstein RA, Celano CM, Wexler D. Positive psychological interventions for patients with type 2 diabetes: Rationale, theoretical model, and intervention de- 
velopment. Journal of Diabetes Research. 2015; 2015:428349. [DOI:10.1155/2015/428349] [PMID] [PMCID]

[30] DuBois CM, Millstein RA, Celano CM, Wexler DJ, Huffman JC. Feasibility and acceptability of a positive psychological intervention for patients with type 2 diabetes. The Primary Care Companion for CNS Disorders. 2016; 18(3). [DOI:10.4088/PCC.15m01902] [PMID] [PMCID]

[31] Khanlarzade F, Asgari K, Amini M. [An investigation of the neuropsychological performance in patients with diabetes type 2 (Persian)]. Journal of Mashhad University of Medical Sciences. 2015; 58(8):459-65.

[32] Seligman MEP, Csikszentmihalyi M. Positve psychology :An introduction. In: Seligman MEP, Csikszentmihalyi M. Flow and the Foundations of Positive Psychology (pp 279-98). Nether lands: Springer; 2014. [DOI:10.1007/978-94-017-9088-8_18]

[33] Nassiri H. [The validity and reliability of the World Health Organization Quality Score and its Iranian version (Persian)]. [MA. Thesis]. Tehran: University of Science and Technology; 2006.

[34] Seligman MEP. Flourish: [A visionary new understanding of happiness and well-being. [A. Kamkar, S. Hojabrian, Persian trans.]. 2th edition. Tehran: Ravan; 2011

[35] Jalali N, Khalouei GH, Mirmhdi SM. Determining the effectiveness of positive psychotherapy on the psychological well-being and quality of life of wives of psychiatric patients. Second National Conference and the First International Conference on Modern Research in the Humanities; 2015 ;Tehran, Iran.

[36] Gholami shahid Z. [The investigating effectiveness of therapy based on positive psychology on improving the quality of life, psychological well-being and hope of life in the patients with Multiple Sclerosis (MS) in Isfahan (Persian)] [MA thesis]. Isfahan: University of Khorasgan; 2015.

[37] Soheylizad M, Yahaghi Amjad E, Amini D, Gholamaliei B. [Relationship between self-esteem, resilience and quality of life in patients with type 2 diabetes in Hamadan in 2015 (Persian)]. Pajouhan Scientific Journal. 2016; 15(1):1-8. [DOI:10.21859/psj-15011]

[38] Diener E, Chan MY. Happy people live longer: Subjective wellbeing contributes to health and longevity. Applied Psychology: Health and Well-Being. 2011; 3(1):1-43. [DOI:10.1111/j.17580854.2010.01045.x]

[39] Sin N, Della Porta M, Lyubomirsky S. Tailoring positive psychology interventions to treat depressed individuals. In: Donaldson S, Csikszentmihalyi M, Nakamura J. (editors). Applied Positive Psychology: Improving Everyday Life, Health, Schools, Work and Society. New York: Routledge; 2011.

[40] Nikmanes Z, Zandvakili M. [The effect of positive thinking training on quality of life, depression, stress and anxiety in delinquent juveniles (Persian)]. Positive Psychology Research. 2013-2014; 2(1):131.

[41] Multaft F, Haji Alizadeh K. [The effect of positive psychotherapy on the quality of life dimensions in patients with psoriasis (Persian)] Paper presented at: The Third Conference of Positive Psychological Updates. 30 April 2012. Bandar Abbas, Iran.

[42] Tabatabaei SM, Manafi E. [The impact of positive psychology on quality of life addicted prisoners (Persian)]. Paper presented at Third International Conference on Recent Innovations in Psychology, Counseling and Behavioral Sciences. 2016 Oct 25-28. Tehran, Iran.
[43] Shoshani A, Steinmetz S, Kanat-Maymon Y. Effect of the Maytiv positive psychology school program early adolescents' well-being, engagement, and achievement. Journal of School Psychology. 2016 57:73-92. [DOI:10.1016/j.jsp.2016.05.003] [PMID]

[44] Yazdi-Ravandi S, Taslimi Z, Ahmadpanah M, Ghaleiha A. Adjustment to diabetes among diabetic patients: The roles of social support and self-efficacy. 2016; 3(1):17-21. [DOI:10.17795/ ajnpp-37470]

[45] Frazier JP, Hilliard M, Cochrane K, Hood KK. the impact of positive psychology on diabetes outcomes: A review .2012; 12(3):111624. http://dx.doi.org/10.4236/psych.2012.312A165 [DOI:10.4236/ psych.2012.312A165]

[46] Snyder CR, Lopez SG. Handbook of Positive Psychology. New York: Oxford University Press; 2007.

[47] Cajanding RJ. The effectiveness of a nurse-led cognitive-behavioral therapy on the quality of life, self- esteem and mood among Filipino patients living with heart failure: A randomized controlled trial. Applied Nursing Research. 2016; 31:86-93. [DOI:10.1016/j. apnr.2016.01.002] [PMID]

[48] Yazdi-Ravandi S, Taslimi Z, Haghparast A, Ghaleiha A. Quality of life in patients with chronic pain disorders: Determinnation the role of intensity and duration of pain. Koomesh. 2016; 17(4):836-43. 